\title{
THE EVOLUTION OF PATENT POLICY: REDEFINING INVENTIVENESS
}

\author{
Authors \\ Hazel V J Moir, The Australian National University (Centre for Policy Innovation), \\ hazel.moir@anu.edu.au
}

\begin{abstract}
Economists assume patented inventions contain new knowledge or know-how. It is this new knowledge which creates the spillover benefits providing dynamic efficiency gains to offset the static efficiency losses of the monopoly grant. Unfortunately this assumption is out-of-date. Over time judges have created myriad policy rules (legal doctrines) circumscribing the patent world's definition of inventiveness. In the patent world a minor difference in design is now taken as sufficient inventiveness to merit a monopoly.
\end{abstract}

This paper discusses the difference between economic and legal approaches to determining if an 'invention' merits a monopoly. It presents detail on the policy rules determining patent grant and investigates the legal decisions underlying these. While some of these doctrines derive from nineteenth century English law, recent Australian decisions have confirmed that most knowledge must be set aside in assessing whether an 'invention' is inventive. Indeed one recent case seemed to grant a patent simply because consumer loyalty experts were ignorant of a well-known IT technique.

The two committees reviewing patent policy in the period since 1980 did not investigate in any detail the impact of doctrines which remove most existing knowledge from tests for patentability. They did make minor recommendations to extend what knowledge can be used, but until 2002 much written knowledge was not allowed to be included in testing for inventiveness. Neither committee discussed the required standard of inventiveness - 'a scintilla'. Low inventiveness standards are also evident in current trade negotiations, with their demands for providing patents for all new uses of known qualities of known substances and processes.

Much 'stakeholder' advice on the patent system comes from interested parties, particularly registered Patent Attorneys. Few economists take an interest in the real-world workings of the patent system and most of the 'dispassionate' advice provided to government on this important innovation policy comes from academic lawyers specialising in the 'intellectual property' field.

IP Australia advises the Commonwealth government on patent policy, and is assisted in this by an advisory body, largely consisting of people who benefit from the patent system. There is little evidence of any attempt to amend statute law when legal judgements undermine the effectiveness of the patent system in delivering economic benefits. The sole exception is a recent amendment which overturns a legal judgement that in low technology fields knowledge embodied in patents should generally be ignored in assessing inventiveness. This contrasts with the competition and tax arenas where responsible bureaucrats regularly recommend improvements to statute law to close loopholes.

The legal focus on whether an invention is 'obvious' - rather than whether it is 'inventive' allows courts to avoid the question of whether the 'invention' embodies any new knowledge or know-how. As a consequence the key economic principle underlying patent policy is ignored in decisions about the grant of patents for specific 'inventions'.

\section{Key Words:}

Innovation policy; patents; inventiveness; regulatory capture 


\section{Paper}

\section{THE EVOLUTION OF PATENT POLICY: REDEFINING INVENTIVENESS}

\section{Introduction}

Economists assume there is new knowledge or know-how embedded in patented inventions. This new knowledge should result in spillover benefits which can provide dynamic efficiency gains to offset the static efficiency losses of the patent system. Unfortunately this assumption is out-of-date. 'Novelty' and 'inventiveness' are used as a proxies for new knowledge, but over time judges have introduced detailed legal doctrines (policy rules) limiting how these proxies work. These ignore the issue of new knowledge. Most existing knowledge is disallowed in assessing novelty, and the quantum of inventiveness required is, in Australia, a scintilla. ${ }^{1}$

This evolution in innovation policy seems never to have been evaluated - case law precedents have generally been simply incorporated into statute law. This paper traces this evolution, following the major legal decisions reducing the quantum of inventiveness required in Australia for grant of a standard patent.

It commences with a short comparison of economic and legal approaches to the issue of patentability (section 2). By focusing on the economic rationale for grant of a monopoly for an invention, one can assess whether the legal proxies adopted are likely to sufficiently mirror the underlying rationale to produce positive economic outcomes. This section also provides a short exposition of the legal approach to patent grant, including the key elements in the complex legal approach to 'inventiveness'. The main section of the paper then reviews the key doctrines and the legal decisions underlying them.

The final section of the paper discusses the extent to which statute law is (or is not) amended to fix problems created by economically unsound decisions. During 2009 IP Australia undertook what it described as an exercise in improving "the Australian patent system as a vehicle to support innovation" (IP Australia 2009a: 1). Issues addressed included the knowledge used in determining inventiveness and part of the test for inventiveness. These consultations fed into the Intellectual Property Laws Amendment (Raising the Bar) Act 2012. Despite these "raising the bar" consultations and amendments the inventive step requirement for an Australian patent remains virtually non-existent. Replacing the proxy tests of novelty and inventiveness with a more direct test of the contribution to knowledge or know-how is considered.

\section{When should a patent be granted? economics and law}

The standard economic rationale for patent policy is that it is expensive to produce new artefacts, but cheap to copy them. If this assumption is correct there will be underinvestment in R\&D. Patent monopolies solve this problem by providing a period in the market when a monopoly price can be charged to recoup the investment costs. If patents work as intended, and this higher price can be charged, then the incentive will lead to a level of investment in R\&D that is closer to a socially optimal level. ${ }^{2}$ The short-term static losses through the monopoly intervention will be offset through the longer-term higher growth rate.

\footnotetext{
${ }^{1}$ One of six factors to be wary of in assessing inventiveness is "failing to recognise that an inventive step requires no more than a scintilla of invention" (Australian Patent Examiner's Manual Section 2.5.1.6 http://www.ipaustralia.gov.au/pdfs/patentsmanual/WebHelp/Patent Examiners Manual.htm).

${ }^{2}$ Some argue that there are few monopoly costs to a patent system, as there are always substitute goods (e.g. Gans, Williams and Briggs 2004). The direct corollary is that if there is no monopoly provided by patents, then patents cannot act as an incentive to shift resources into inventive activity, and are therefore ineffective.
} 
This economic objective of patent law is not spelled out in Australia's patent statute, ${ }^{3}$ but is clear in the original English statute authorising the grant of monopolies for inventions. That law was created in the context of limiting actions which breached the Common Law right to carry on a trade - parliament intervened to limit the right of monarchs to grant monopolies. An exception to the ban was the grant of patent monopolies for inventions, or as the 1623 Statute of Monopolies put it "any manner of new manufactures". Australian patent law derives from this exception to the Statute of Monopolies, and the current Patent Act still defines a patentable invention as "a manner of manufacture within the meaning of section 6 of the Statute of Monopolies" (section 18(1)(a)). The wording of Section 6 is:

"the sole working or making of any manner of new manufactures within this realm, to the true and first inventor and inventors of such manufactures, which others at the time of making such letters patents and grants shall not use, so as also they be not contrary to the law, nor mischievous to the state, by raising prices of commodities at home, or hurt of trade, or generally inconvenient."

At the time this was drafted the term "inventor" included those importing something new from overseas as well as those inventing domestically. The proviso "which others at the time of making ... shall not use" emphasised that requirement that the artefact must be new, i.e. that it should not affect what was already being done at the time. The importance of newness was further emphasised by the proviso "so as also they be not contrary to the law" which one of the principal drafters, Lord Coke, indicated meant that improvements were excluded from the monopoly exception as they had the capacity to contravene the right to carry on a trade. The other provisos also indicate a strong emphasis on the importance of the monopoly effectively contributing positively to net economic well-being. ${ }^{4}$ This is particularly clearly spelled out on the 1641 Massachusetts code of laws:

"There shall be no monopolies granted or allowed among us, but of such new inventions as are profitable to the country, and that for a short time" 5

It is clear then that the original policy focused on the objective of increasing national economic well-being by encouraging innovation, while ensuring that this was not at the expense of existing economic activities. The focus on absolute newness and the several provisos combined to ensure effective balance in the original patent policy.

Over the centuries these strict limitations have been watered down. Two decisions are of particular importance. In 1776 Lord Mansfield made a pragmatic decision to allow patents for improvements, on the grounds that otherwise most monopolies granted would become invalid (Walterscheid 1995c: 853). In 1842 patent monopolies were extended from products to processes. ${ }^{6}$ Processes are generally far harder to define than products, and as a consequence the exact boundary of the granted monopoly can be very unclear, leading to inadvertent trespass by other inventors.

With these two changes the definition of a "new manner of manufacture" became less clear and courts commenced developing rules to assist in determining if an 'invention' was patentable. Nonetheless, in 1954 in Australia the underlying Common Law principle remained:

"Obviously, a monopoly will not be granted, or the grant will not be valid, if it prevents any person from doing what he had been previously accustomed to do. Such a grant would be contrary both to Common Law, and to the provisions of the Statute of Monopolies"

(Curtis and Lahey 1954: 7)

\footnotetext{
${ }^{3}$ Nor in other patent statutes, e.g. the UK, the USA and the European Patent Convention (EPC).

${ }^{4}$ See Walterscheid (1995a, 1995b) for a thorough analysis of this early stage in English patent law, including

Lord Coke's 1628 Institutes of the Laws of England.

${ }^{5}$ Article 9. http://history.hanover.edu/texts/masslib.html

${ }^{6}$ Crane v Price 1 W.P.C. 393 (Curtis and Lahey 1954: 2)
} 


\section{2a. The economic perspective}

While patent policy and law establishes a general principle of the grant of a monopoly for an invention, each application raises issues as to whether it merits a monopoly. Will that grant add to national economic well-being? From an economic perspective a clear operationalisation of this question is whether the invention generates sufficient new knowledge or know-how to generate spillover benefits to offset the monopoly losses. From a policy perspective a critical view is additionality - will the monopoly grant actually lead to R\&D investment that would not otherwise take place? If it simply generates windfall gains there is a clear economic loss. Basing patent grant on the additionality principle has been too hard for policy makers, despite its obvious net benefits. The fall-back, new knowledge, is more likely to reduce net benefit, but nonetheless does focus on the key variable. Within patent law this is operationalised as 'novelty' and 'inventiveness'.

Once a decision had been made that the application merits grant of a patent, one major condition is attached to that grant - the knowledge must be made public. In the Statute of Monopolies the monopoly period was 14 years - time to train two cohorts of apprentices. During the eighteenth century a requirement for a written description was introduced, and this condition of grant has been written into statute law. Many lawyers (including judges) take the view that the condition of the grant - the disclosure of the new knowledge to the public - is the objective of the patent system. This is fine where the focus is on the new knowledge, but where focus shifts to simple disclosure it can be problematic. The absence of any stated goal for patent policy in the patent statute makes it is easy for judges to make decisions which take no account of the patent policy goal of benefiting the nation.

This failure is very clear illustrated in two recent (2005 and 2006) Australian judgements on an innovation patent application for a system of hiding one's assets from one's legitimate creditors (the Grant case). The original Federal Court judgement by Branson, J did in fact focus on the goal of patent policy, but on appeal this analysis was substantially criticised by the Full Federal Court.

Branson J's decision is worth quoting at length as it is the most economically sound patent judgement in Australia in some time and the only one which considers the objectives of patent policy.

"Section 6 of the Statute of Monopolies was intended to allow the grant of monopolies limited in time where the public benefit derived from the grant of the monopoly might be expected to outweigh the public cost of the resultant interference with free trade. The same principle underlies modern legislation authorising the grant of patents.

"The principle which has been developed for the application of s6 of the Statute of Monopolies that seems to me to be critical in this case is the principle that an invention should only enjoy the protection of a patent if the social cost of the resulting restrictions upon the use of the invention is counterbalanced by resulting social benefits. This principle is derived from the theoretical justification for the grant of a patent; that is, the assumed value of inventive ingenuity to the economy of the country. The monopoly granted by a patent to an inventor is assumed to serve the public interest both by rewarding, and thus encouraging, inventive ingenuity and by ensuring the disclosure to the public of a new article or process."

(Grant $v$ Commissioner of Patents [2005] FCA 1100, 13, 20; emphasis added)

This analysis was severely criticised by Justices Heerey, Kiefel and Bennett in their dismissal of the Grant appeal, on different grounds. They said:

"It is not relevant, in our view, that some may think that a method or product will not advance the public interest. Once a product or process has been patented, its use is subject to the laws of the land, such as (to take but a few examples) those concerned with environmental protection, pharmaceutical product approval and occupational health and safety.

"Nor is the Court in a position to determine the balance between social cost and public benefit. Parliament has already made that judgment, as its predecessor did in 1623, by rewarding innovation with time-limited monopoly."

Grant $v$ Commissioner of Patents [2006] FCAFC 120, $44-45$ (emphasis added) 
This is an extraordinary statement. In the first quoted paragraph it confuses issues of patentability with issues concerning the rights granted to the holder of a valid patent, totally missing the point that the grant itself should be for an invention conferring a net benefit on the nation. It goes on to confuse decisions about overall policy (made by parliament) with decisions on specific cases (to be made by courts). Parliament has certainly decided that it wants a patent system, providing a monopoly incentive to invention. But it surely does not want this system to operate to reduce Australia's well-being. If the patent system is to deliver a benefit, then most granted monopolies must be for inventions where social benefits exceed social costs. Oversight of law is handled by the courts, and it is extraordinary that the courts are unable to see the difference between the decision in regard to a specific 'invention' and the overall outcome for the patent system as a whole.

\section{2b. Development of patent law}

Patent law developed into statute law during the nineteenth century. As the volume of patents grew, so too did disputes about ownership and boundaries and a body of case law began to build up. These were normally disputes between private parties as to whether there was patent infringement, normally also leading to a counter-claim that the patent had been invalidly issued. In English, and thus Australian, law there is no procedure for the public interest to be represented in such cases. Towards the end of the nineteenth century a new legal principle was also adopted in England - stare decisis ${ }^{7}$ - to treat prior legal decisions as binding interpretations of the law. In combination with the lack of any public interest consideration in individual cases, the new stare decisis doctrine codified doctrinal rules as patent policy. These codified rules were adopted into statute law without any assessment of their economic impact. As will be seen these rules are not always economically sound.

\section{2c. The legal perspective on assessing novelty and inventiveness}

Legal analysis of whether an invention can validly be granted a patent falls under a number of headings, each of which considers the key term "any manner of new manufactures" from a different perspective. In early UK patent law subject matter and inventiveness were entwined with the public interest considerations basic to both Common Law and the Statute of Monopolies. It is hard to separate these elements out in early decisions (Bochnovic 1982). ${ }^{8}$ Now these concepts are treated quite separately and issues which frequently arise in infringement cases - where patent validity is challenged - are patentable subject matter (is it a manner of manufacture?), novelty (is it new?) and inventiveness (how new?). The analysis here focuses on novelty and inventiveness common concepts across most patent systems. In particular it assesses whether these are good proxies for the underlying principle of the generation of new knowledge or know-how.

A student of innovation might well consider novelty and inventiveness part of the same continuum - a question of determining just how much inventiveness (or new knowledge) was sufficient to ensure benefits exceeded costs and so merited a patent. However under codified patent law novelty and inventiveness are two quite different concepts, applied against different bodies of knowledge with different decision-making rules.

\section{Existing knowledge}

Patent law presumes a good, readily available, library of material demonstrating the current state of knowledge (Cohen and Lemley 2001). Naturally this library is most deficient in new fields of

\footnotetext{
${ }^{7}$ Stare decisis et non quieta movere (stare decisis for short) literally means "[t]o stand by things decided, and not to disturb settled points." Black's Law Dictionary 1443 (8th ed. 2004).

${ }^{8}$ Public interest considerations were evident as late as 1968 when a Hearing Officer, rejecting an application for software to solve linear programming problems more quickly said: "It would certainly be mischievous to the State and generally inconvenient if, after investing a million dollars in a computer, the owner were to find himself prevented from operating it efficiently, or in any other manner he may wish, or with any degree of privacy or secrecy he may desire." British Petroleum Co. Ltd.'s Application (1968) 38 AOJP 1020: at 1021.
} 
technology, where most existing knowledge is as yet uncodified. The presumed library forms the 'prior art' against which novelty and inventiveness is tested. Given the purpose of a patent system, the knowledge base would be presumed to be the existing body of knowledge. Not in patent law. Not all knowledge is permissible as the basis for testing novelty and inventiveness. And exactly which sub-set of knowledge is used as the basis for the decision differs between the tests of novelty and inventiveness.

\section{Novelty}

The novelty test now rarely acts to preclude grant of a patent. This is partly because applicants can now amend patent specifications, partly because the test is against one written document at a time and partly because quantum of required difference seems non-existent.

When an examiner rejects an application for want of novelty, the applicant simply makes an amendment - usually the addition or removal of a minor feature - and then argues the application now differs from the earlier document. There is a doctrine of "mechanical equivalence" which should mean that minor variations do not confer novelty. This principle is that if substitution of one element for another results in a simple functional equivalent of the earlier invention, it lacks novelty. There are some exceptions: where the new element is itself inventive; if there are difficulties to be overcome in the replacement; or where a "new combination" arises. In discussing whether a technical equivalent can be deemed to be a new combination, the Australian patent examiner's manual indicates that the critical question is whether the essential character of the device has been changed. ${ }^{9}$

This rule seems to have little practical effect in preventing grant of obvious patents. Examiners do cite it, for example in a spare part procurement patent. ${ }^{10}$ The attorney amended the claims but disagreed that "the step of asking the specific questions required in the claimed method is a technical equivalent to the practice in the [prior] document of assessing a potential seller's spare parts surplus by directly examining the potential seller's inventory and product planning databases." To the ordinary person these two approaches seem equivalent, but the patent was accepted within a week of this response being received by the examiner.

There does not appear to be any economic evaluation of how novelty actually operates. The 1984 review of Australia's patent system recommended that, except for explicit cross-referencing, the prohibition on combining evidence should remain. No reasons were given.

\section{Inventiveness}

The inventive step test emerged at around the same time as the novelty test was emasculated through the limitations on existing knowledge. It was only adopted into statute law many years later (Bochnovic 1982: 9). Bochnovic indicates that the first British case where a patent was held invalid for want of an inventive step was in $1868 .^{11}$

Since April 2002 Australian patent law has judged inventiveness relative to common general knowledge in that technology in Australia and knowledge in relevant published documents. In addition to defining what knowledge can be used, there are many rules about how it can be used. These rules do not address any aspect of the issue of contribution to knowledge or know-how. As a result it is perfectly possible for an application to pass all the inventiveness rules yet fail to contribute any new knowledge or know-how.

\footnotetext{
${ }^{9}$ Patent Examiner's Manual section 2.5.3.2.

${ }^{10}$ Application 2004202060, priority May 2004. In application 2003240981 success in rejecting the technical equivalent argument seems to rest on the earlier invention being used for purchasing physical not digital goods.

${ }^{11}$ White v Toms, (1969) 37 LJ Ch 204.
} 
With the centrality of the issue of 'is it obvious?' is the question of 'obvious to whom?'12 The appropriate judge has been determined to be a person with ordinary skills in the relevant technology. Patent law uses this hypothetical person to provide a perspective from which to judge obviousness. Over time various qualities have been ascribed to this judge.

The rules include who the judge is; what characteristics s/he possesses; what knowledge s/he may use in determining inventiveness; the quantum of inventiveness (a scintilla); other aspects of the mental model used in considering obviousness; and special rules regarding the use of well-known elements and processes in new combinations. ${ }^{13}$ Also relevant are several doctrines which were developed to try and limit the grant of monopolies for uninventive inventions, particularly the synergy test for combinations, the analogous use test and new uses of known substances.

\section{2d. Overall balance and risks of error}

It is unreasonable to expect that there will never be any errors in decisions to grant or refuse patents. However it is also reasonable to consider whether there is a greater public interest in risking grant of a monopoly for an uninventive invention that refusing one for an inventive invention (Jensen and Webster 2004). As the recent Grant case shows, there are many opportunities for the owner of a rejected application to challenge the refusal. ${ }^{14}$

There is a substantial asymmetry in the incentive to litigate a patent between the patent-holder and alleged infringers, allowing many uninventive patents to remain unchallenged. ${ }^{15}$ There are many biases against appealing the grant of monopolies for uninventive invention (Thambisetty 2008: 3032). A single party has to bear all the costs, while if the appeal is successful the benefits of eliminating the unjustified monopoly flow to all innovators working in that field. It would be more appropriate for the would-be monopolist to bear the cost of the appeal, as the party seeking to limit competition.

From the perspective of the public good and the importance of achieving balance in the patent system between costs and benefits, the preferred bias would be towards the rejection of inventive patents, rather than the grant of monopolies for uninventive inventions. Unfortunately as the system has developed, both in Australia and in many overseas countries, it appears that in each of the myriad decision rules and procedures there is a strong bias to avoiding the rejection of inventive patents. As the Federal Trade Commission concluded in respect of the US system:

"A plethora of presumptions and procedures tip the scales in favor of the ultimate issuance of a patent, once an application has been filed."

(US FTC 2003: 8)

This directly implies the frequent grant of monopolies for uninventive inventions.

\section{Key legal decisions on novelty and inventiveness}

\section{3a. The knowledge base}

For both the novelty and inventiveness tests, relevant existing knowledge is limited to the technology field of the invention. This limitation operates very tightly in Australia, particularly for the inventiveness test. Further, the allowable field of technology has become very narrowly

\footnotetext{
${ }^{12}$ This approach, the so-called 'Cripps question', was introduced in Sharp \& Dohme v. Boots Pure Drug Company in 1928, and embodied in statute law in the UK in 1932.

13 There are additional detailed rules for patent examiners, such as the reverse onus of proof and the standard for weighing evidence.

${ }^{14}$ The Grant application, discussed above in the text, went through four appeals and was rejected on different grounds each time (see Tyacke and Webb, 2007).

15 While Australia has a pre-sealing opposition process, this presumes firms will actively monitor acceptances, at some substantial cost. It is also interesting that fees for opposing a patent $(\$ 1,200)$ are higher than fee for obtaining a patent (\$990) (see http://www.ipaustralia.gov.au/get-the-right-ip/patents/timeand-costs/fees/).
} 
circumscribed. A clear illustration is the 2001 Federal Court Welcome case where all parties to the dispute agreed that the essence of the invention - dynamic storage - was well-known within the information technology field. ${ }^{16}$ However the use of this well-known technique was in a smart card for rewarding consumer loyalty. Heerey $\mathrm{J}$ took the view that consumer loyalty workers would not reasonably have known about dynamic storage so to them their patent was indeed inventive and thus valid. This is despite the fact that the process would be implemented by IT specialists to whom dynamic storage is obvious. The decision seems remarkably like saying ignorance is a ground for grant of a government monopoly. Costs and damages were awarded to Welcome RealTime and Catuity has gone out of business.

This extremely narrow approach to defining the relevant field of technology is also evident in the USA where Bagley (2001) has demonstrated how technology fields are now so narrowly construed that most relevant existing knowledge is ruled inadmissible in the obviousness (inventiveness) test. Nonetheless in the USA relevant existing knowledge outside the exact field of endeavour can be used in testing for obviousness if it is reasonably pertinent to the particular problem addressed. ${ }^{17}$ This does not seem to be the case in Australia because of the key role the PSA plays in determining eligible existing knowledge (see Section $3 c$ below).

\section{3b. Novelty}

Originally the test for newness was against whether an invention had been publicly worked within living memory, a policy expanded in 1778 to include disclosure through publication. The "within living memory" condition was adopted into Australian statute law - patents over 50 years old did not count as existing knowledge. This was only removed from the Australian statute in 1990. It remains in the New Zealand Patents Act 1953, Section 13(1).

A mere two years after the requirement for a written disclosure of the invention a UK court determined that the existing knowledge against which newness should be tested should be measured one piece of knowledge at a time..$^{18}$ Because of the stare decisis approach, which confers a binding authority on each new legal doctrine, this view of one judge was adopted into UK law and so into Australian law. Current statute law states that this single publication is to be read in the light of common general knowledge in the field. On rare occasions two pieces of knowledge can be considered for the newness (now novelty) test, but only in highly constrained circumstances. A cross-reference from one document to another is an insufficient reason for two documents to be considered together. ${ }^{19}$ Two documents can be considered if and only if a person skilled in the technology would treat them as a single source. This effective limitation to a single written document, combined with the right to endlessly amend specifications, means it is extremely easy to overcome a novelty objection.

Further, as the Australian patent examiner's manual advises,${ }^{20}$ every essential element of the claim must be anticipated for there to be a lack of novelty. Where an invention has a number of elements, frequently the case with software and business method 'inventions', the likelihood of it being deemed exactly the same as a previous invention is thus substantially reduced, even if every separate element can be found in previous inventions. "Combination" inventions are discussed further below.

\footnotetext{
${ }^{16}$ Welcome Real Time SA v Catuity Inc (2001) 51 IPR 327.

${ }^{17}$ See, for example, the USPTO examiner's reports in US application 10/595439.

${ }^{18}$ Von Heyden v. Neustadt (1880) 50 L.J.Ch. 126 at 128; 14 Ch.D. 230. This decision was re-emphasised by Viscount Dunedin in 1929 (Pope Appliance v. Spanish River). It was subsequently challenged, but the doctrine was re-affirmed by the UK Court of Appeal (1952) and the House of Lords (1956) (Bochnovic 1982: 20-21).

${ }^{19}$ Patent Examiner's Manual, 2.4.4.4.

${ }^{20}$ Patent Examiner's Manual, 2.4.10.
} 


\section{3c. Inventiveness: the decision-making rules}

The legal system considers whether a patent is inventive by considering whether or not it is more than a technical equivalent or "workshop improvement". ${ }^{21}$ This is done based on a set of rules set up to determine if the invention is obvious, not whether it is inventive. The issue of whether it contains any new knowledge or know-how if not considered at all, particularly at the stage when the application passes through the patent office. Patent examiners are warned that all aspects of assessing the inventive step must be done from the perspective of the relevant person skilled in the technology. Only if that person would consider knowledge relevant in addressing the problem addressed by the patent application may the examiner use that information in assessing inventiveness. ${ }^{22}$

\section{Who judges obviousness: the PSA}

Courts have developed a "problem-solution" approach to assess inventiveness to attempt to avoid problems of hindsight. This involves determining the problem posed in the patent specification, without using in any way the solution proposed in the specification. This problem area then allows the relevant skilled person to be identified. The person skilled in the 'art' (technology) (PSA) is determined in terms of the technology field of the problem not of the solution. While the PSA may look at knowledge in related fields for the solution, examiners are warned that "[a]s the person skilled in the art is non-inventive, it is unlikely that the person would look for a solution in arts remote from the problem."23

\section{The attributes of the obviousness judge (PSA)}

Given that we are talking about patent law - that is about the grant of monopolies for inventions one of the more astonishing rules is that the judgement about lack of inventiveness must be made by a person possessing no imagination or ingenuity. I have been unable to trace the reasons for this rule, or even when it first arose. I can merely speculate that it may relate to another extraordinary rule - that the quantum of inventiveness required for a patent in the UK and in Australia is a mere scintilla (see below). ${ }^{24}$

The UK patent examiner's manual advises that the PSA "should be taken to be a person who has the skill to make routine workshop developments but not to exercise inventive ingenuity or think laterally". ${ }^{25}$ As van Caenegem comments in his recent Australian text on 'intellectual property' law, in relation to this "a typical uninventive worker" rule:

"This again is rather surreal, certainly in a field where inventiveness is a common attribute of every typical worker, as for instance at the higher end of scientific research. Then all that is required is that the invention, as a step onward from the prior art, is not obvious. No ingenuity, revolutionary insight, creativity or major step forward need be shown; some small inventive spark is enough, and it matters not whether that inventive step resulted from a sudden insight, or from careful study, reflections and research"

(van Caenegem 2007: 85, emphasis added)

\footnotetext{
${ }^{21}$ A workshop improvement is "an alteration to an existing device which the person skilled in the art would have come to as a matter of routine, "proceeding along previous lines of inquiry and having regard to what was known or used" (Nicaro Holdings Pty Ltd v Martin Engineering Co 16 IPR 545)." Patent Examiner's Manual, 2.5.3.3.

${ }^{22}$ Patent Examiner's Manual, 2.5.1.1.

${ }^{23}$ Patent Examiner's Manual, 2.5.2.4.

${ }^{24}$ The Patent Examiner's Manual cites a 1972 UK case that the PSA should be "incapable of a scintilla of invention", Technograph Printed Circuits Limited v Mills and Rockley (Electronics) Limited (1972) RPC 346 (Section 2.5.2.5.5).

${ }^{25}$ Para 3.21 (http://www.ipo.gov.uk/practice-sec-003.pdf) citing Laddie J in Pfizer Ltd's Patent [2001] FSR 16 at paras 62 and 63 and the Court of Appeal in Technip France SA's Patent [2004] RPC 46 (Laddie J at paras 6-10).
} 
We live in a world where innovation is the norm not the exception. Patent policy does not yet seem to have caught up with this. ${ }^{26}$ Rules such as requiring inventiveness to be judged by the kind of person who would never be employed at the forefront of invention sets up one of many biases towards the grant of monopolies for uninventive 'inventions'.

However the requirement that the PSA lacks imagination pales into insignificance against the rule that an invention is obvious only if an inventor would be led as a matter of course towards the outcome with every expectation of success. This decision-making rule implies that if normal experimentation is needed to achieve a new outcome, then regardless of how unsurprising (or lacking in new knowledge) it is, then it is inventive. This is discussed below.

\section{The knowledge possessed by the PSA}

The allowable knowledge base for the inventiveness test centres round the normal knowledge base of the PSA. This is defined as that person's "common general knowledge" and any other documents that that person could "be reasonably expected to have ascertained, understood, regarded as relevant and ... combined ..." (Patents Act 1990, Section 7(3)). Until 2006 the Patent Examiner's Manual presumed that this knowledge set included patent literature. This interpretation was called into question by the 2006 Emperor Sports decision which effectively excised from the inventiveness knowledge base most patented knowledge in fields where the normal worker would not think of looking at patent databases. ${ }^{27}$ This surreal outcome is a clear, exact and narrow application of the words in Section 7(3) of the Australian Patents Act 1990 (see Appendix 1). Effectively it meant that all patented knowledge in low-technology fields was eliminated from the existing knowledge base when inventiveness is assessed.

The Emperor Sports decision is interesting for what it shows about the context within which legal judgements about patent disputes are made. Although it is self-evident that the context is seeking a monopoly for an invention, this context is not brought to bear in interpreting the statutory language about the knowledge that the person skilled in the technology - here a Rugby League or Australian Rules coach, referee, umpire or administrator - would find and understand. The Federal Court judges in the Emperor Sports case did not consider that, faced with the issue of the patented football artefact, it would be reasonable for the skilled footballer to consider consulting patent databases. In other words, existing knowledge is to be determined outside the context of seeking a patent monopoly.

The Emperor Sports case radically reduced the quantum of inventiveness required for grant of a patent in low (or no) technology fields. It therefore directly increased the probability that the patent system would cause economic harm rather than provide economic benefits. The decision raised particular problems in regard to the trend towards the granting patents outside any field of technology. In these fields it effectively ensured an inventive step so low as to be practicably indiscernible. This is the major area where the Patent Amendment Act 2012 actually raises the height of the inventive step, amending the wording which led to the Emperor Sports decision. Now existing pieces of knowledge can use for the inventiveness test if the PSA could reasonably be expected to have combined them.

Another interesting insight into how the artificial construct of the PSA lowers the height of the inventive step is provided by the 2007 Lockwood case. Here the High Court found that it was not reasonable to consider known characteristics of storeroom locks in determining the inventiveness of a rim-mounted lock. ${ }^{28}$ The decision was based on the evidence of witnesses skilled in the manufacture and design of locks who advised they would not have considered looking to the

\footnotetext{
${ }^{26}$ Though the US Supreme Court has recently indicated that the "person skilled in the art" should have "normal" creativity (KSR v Teleflex, 127 S. Ct. 1717 (2007): at 1741-2).

${ }^{27}$ Commissioner of Patents v Emperor Sports (2006) 225 ALR 407;(2006) 67 IPR 488;[2006] FCAFC 26.

${ }^{28}$ This 2007 decision was made under the terms of the Patents Act 1952. However the issues involved in the decision did not include the differences between the two Acts in the knowledge that could be used by the PSA, rather it was based on evidence of the PSA witnesses that they did not think of using that knowledge. Lockwood Security Products Pty Ltd v Doric Products Pty Ltd (No 2) [2007] HCA 21, at 157-167.
} 
storeroom lock feature, a lock release means, to solve a problem with rim-mounted locks whereby people were locked into their own homes. So considering the question of relevant knowledge from the 'objective' perspective of the PSA (as embodied in specific human witnesses) eliminated knowledge which would have been elicited by the even more objective approach of asking the question "what is known in the field of the manufacture and design of locks?" The issue of whether it required ingenuity to take this characteristic from one area of lock manufacture and apply it in another never arose. Nor did the issue of whether this new combination of known elements gave rise to any surprising outcome (a lock which did not lock you into your own home seems a rather basic requirement).

The use of the PSA construct in determining relevant knowledge effectively meant that the High Court defined the technology field so narrowly that knowledge from one area of lock manufacture and design was not allowed to defeat obviousness in another area of lock manufacture and design. Clearly, despite the views of the PSA witnesses, there was no new knowledge or know-how in the patented invention. But because patent statute law is now wholly drafted round concept of the PSA and the proxy terms 'novelty' and 'inventiveness' the issue of any contribution of knowledge or know-how never arose.

\section{A scintilla: the quantum of inventiveness for an Australian patent}

In considering inventiveness across the UK, USA and Canada Bochnovic notes the requirement for a scintilla of inventiveness, such that an "alleged invention need only pass the line by a "scintilla" in order to be valid and patentable" (Bochnovic 1982: 37). This is an unexceptional position. If it is determined that a certain quantum of inventiveness is likely to confer sufficient benefits to offset the monopoly costs, then passing this line by a scintilla suffices to merit grant of a patent.

Unfortunately passing the standard of inventiveness by a scintilla seems to have become having a scintilla of inventiveness - a very different thing. The Australian Patent Examiner's Manual cites a 1929 UK case that "it is ... practically impossible to say that there is not present that scintilla of invention necessary to support the Patent". ${ }^{29}$ If the courts think that a scintilla of inventiveness is enough to provide sufficient benefits to overcome the costs of granting a patent, it is not surprising that they are making decisions which seem irrational from an economic or national interest viewpoint.

\section{How the PSA judges inventiveness: led as a matter of course}

If the PSA, when faced with the problem addressed in the patent, would come up with an identical solution then the patent is deemed obvious and so invalid. In all other circumstances the solution is not obvious, even if the patent combines well known elements and there is nothing surprising in the outcome of combining these known elements.

Lawson considers that the combined effect of a number of Australian High Court decisions is to effectively eliminate the inventive step (Lawson 2008). A key decision under-pinning this view is Aktiebolaget Hässle ${ }^{30}$ which, he argues, makes it impossible to prove lack of inventiveness. Lawson argues that the Court's requirement that "an inventor would be directly led as a matter of course to the invention in the expectation of success" as the basis for showing obviousness creates a very low inventiveness threshold (Lawson 2008: 56 emphasis added). It rules as inventive any situation where experimentation among a range of likely options would be regarded as likely to lead to success. This very narrow view of inventiveness recently received commented by a UK judge as indicating an extreme pro-patent view of obviousness:

"currently Australian courts seem to be taking a very propatent view of obviousness and [...] patents are being upheld there which are not upheld elsewhere. The Hässle case and the Viagra case, Pfizer v Lilley (held by the Federal Court of Appeal non-obvious though invalid on other grounds) are perhaps examples of this"

\footnotetext{
${ }^{29}$ Section 2.5.3.10.5, citing Samuel Parkes \& Co Ltd v Cocker Brothers Ld (1929) 46 RPC 241 at page 248.

${ }^{30}$ Aktiebolaget Hässle v Alphapharm Pty Ltd (2002) 212 CLR 411.
} 
[2007] EWHC 1040 (Pat): at 43

The High Court Lockwood $v$ Doric case also re-emphasised that the standard of ingenuity required to distinguish between obviousness and inventiveness was "whether or not the skilled person would be led directly as a matter of course to try a particular approach with a reasonable expectation of success" (IP Australia 2009b: 12). The 'invention' at issue delivered no new knowledge. It simply took a known feature from storeroom locks - a feature which appears particularly relevant to the problem being addressed - and combined this with known features of rim-mounted locks.

\section{3d. Doctrinal rules to prevent obvious patents}

There are a number of legal concepts which have been developed to try to ensure that patents are not granted for uninventive applications. Three such doctrines are the tests regarding analogous use, new use of old substances and mechanical equivalence (IPCRC 2000: 154). In policy and practical terms these doctrines were very similar - they operated to exclude trivial variations and the types of incremental inventions that a very large number of persons are likely to discover simultaneously. These long-standing rules seem to be being eroded.

\section{Analogous use}

The earliest rejection of an invention on the grounds that it was simply an application of a wellknown thing to an analogous use was in 1838. The claim was for a wheel for use in railway carriages (Brennan and Christie 1997: 239).

"It would be a very extraordinary thing to say, that because all mankind have been accustomed to eat soup with a spoon, that a man could take out a patent because he says you might eat peas with a spoon. The law on this subject is this: that you cannot have a patent for applying to a well-known thing, which might be applied to 50,000 different purposes, for applying it to an operation which is exactly analogous to what was done before."

(1838) 3 Hayward's Patent Cases 125, 141

The principle was considered by the House of Lords in 1865, and in his judgment the Lord Chancellor said:

"Upon that I think that the law is well and rightly settled, for there would be no end to the interference with trade, and with the liberty of any mechanical contrivance being adapted, if every slight difference in the application of a well-known thing were held to constitute a patent ..." 31

In contrast, in 1930, a UK refusal to grant a patent was overturned in respect of a known product (hardened glass) used for a suitable purpose: vehicle windshields. It was acknowledged that this was contrary to prior authority (Brennan and Christie 1997: 242). Nonetheless in Australia the High Court continued to uphold the analogous use principle as late as 1959:

"If stainless steel and its properties were known, and many kinds of articles had been made of it, it would not be possible for a man to claim a monopoly for making kitchen sinks of stainless steel merely because he was the first man who ever thought of doing this. ... It is not an inventive idea for which a monopoly can be claimed to take a substance which is known and used for the making of various articles, and to make out of it an article for which its known properties make it suitable, although it has not been used to make that article before.

Commissioner of Patents v Microcell, (1959) 102 CLR 232, 248 and 249 (emphasis added)

\footnotetext{
${ }^{31}$ Hamilton E. Harwood and Another v The Directors, etc of the Great Northern Railway Company, (1865) 11 HLC 654 at 682-3, 11 ER 1488 at 1499 (emphasis added).
} 
The Australian Council on Intellectual Property (ACIP), ${ }^{32}$ in discussing patentable subject matter argued that analogous use covers "improvements to existing processes or devices which replaced a particular element with another element, the properties of which were already known" (ACIP 2008: 18). They contrast this with "combinations of two or more elements" giving rise to a new and useful form. ACIP concludes that the analogous use principle applies where the invention is classified as a use but not a combination. This is an extremely narrow reading of the analogous use exception, and in practice the Australian Patent Office appears not to use the analogous use doctrine. ${ }^{33}$ The essence of the invention in Welcome Real Time $v$ Catuity was the use of a wellknown software technique (dynamic storage) applied in the exactly suitable context of consumer loyalty cards.

\section{New uses of old substances}

Some 50 to 60 years ago the principle that one cannot obtain a patent for new uses of old substances was straightforward. The then Australian Commissioner of Patents, speaking at a major scientific meeting in 1952, noted that "the discovery of an unknown property in a known material is not patentable, primarily because no manufacture in the sense of a physical thing is disclosed" (Wilmot 1954: 3).

This principle was overturned by the High Court in 1959 on the basis that a surprising new effect had been discovered in a known substance and that this had a valuable economic effect. ${ }^{34}$ This $N R D C$ decision revolved around the issue of what constituted a manner of manufacture - a subject beyond the scope of this paper. As regards inventiveness it set a new policy rule that new uses of old substances could, at least in principle, be patented. It is clear from the judgement that the High Court considered this new use extremely inventive, albeit that the inventiveness was in the discovery not the implementation process. The NRDC judgement - particularly the argument that the modern test for whether something is a manner of manufacture should be whether it is useful in any field of economic endeavour - has been globally influential and it cited in several judgements in other Common Law countries.

The 2004 Australia US Free Trade Agreement (AUSFTA) requires that Australia provide patents for new uses of old substances, though normal novelty and inventiveness tests must be passed. The demand for patentability for new uses of known things is now part of the USA's active monopoly agenda in free trade fora. A leaked draft of the Trans Pacific Partnership Agreement (TPP), currently being negotiated, states:

"patents shall be available for any new forms, uses, or methods of using a known product; and a new form, use, or method of using a known product may satisfy the criteria for patentability, even if such invention does not result in the enhancement of the known efficacy of that product." 35

\section{Combinations and workshop equivalents}

Many inventions take known elements and combine these in different ways. These "combination" patents raise substantial policy challenges. As they take only known elements they appear to offer no benefits to offset the costs of the monopoly, as there is no new knowledge. Two doctrines

\footnotetext{
${ }^{32}$ Largely composed of patent system beneficiaries (see Appendix 2).

${ }^{33}$ In a study of 72 business method patents, most of which combine existing processes or use known processes in marginally different environments, the analogous use doctrine was never raised as a ground for rejection, despite the dataset including such well-known processes as audit, benchmarking and writing sales contracts.

${ }^{34}$ National Research Development Corporation v Commissioner of Patents [1959] HCA 67; (1959) 102 CLR 252.

35 Article 8 (1). http://keionline.org/sites/default/files/tpp-10feb2011-us-text-ipr-chapter.pdf. The wording particularly the reference to any lack of increased efficacy, demonstrates that this draft derives from the pharmaceutical industry and suggests that, inter alia, it may be directed at Brazil's requirement that a new pharmaceutical product provide an improved health outcome as a condition of patent grant.
} 
developed to deal with combinations of known elements. One is the doctrine of workshop improvements, noted above. A workshop improvement is "an alteration to an existing device which the person skilled in the art would have come to as a matter of routine."36

A more important policy to prevent the grant of uninventive re-combinations of known elements was the 'synergy' doctrine, still used in the UK (and indeed in all countries subscribing to the European Patent Convention). The synergy doctrine requires that a combination of known elements produce either a new and inventive/unexpected result or a result that is greater than the sum of its parts.

This doctrine was over-ruled in Australia in 1980. The High Court ruled that in considering combinations of known elements:

"The proper question is ... whether it would have been obvious to a non-inventive skilled worker in the field to select from a possibly very large range of publications the particular combination subsequently chosen by the opponent in the glare of hindsight ... The prior existence of publications revealing those integers, as separate items, and other possible integers does not of itself make an alleged invention obvious. It is the selection of the integers out of, perhaps many possibilities, which must be shown to be obvious. ... The opening of a safe is easy when the combination has been already provided."

Minnesota Mining and Manufacturing v Beiersdorf (1980) 144 CLR 253 at 293 (emphasis added)

The challenges of technological innovation are quite different from and far more varied than opening a combination safe. This rather simplistic analogy has been used to create a policy rule that unless a specific combination of known elements is already documented in writing it cannot be rejected as uninventive by an Australian patent examiner. Further this is used to support an additional rule - that unless people skilled in the art would come up with only that combination, then it is not obvious under patent law. This suggests that the more old ideas you combine, the less likely it will be that a patent office can reject your combination as obvious. From an economic policy perspective, this development in patent law appears dysfunctional.

Given that the onus lies with the government to disprove inventiveness (See Section 7 of the statute), ruling that inventiveness exists in new combinations of known elements except in very restrictive circumstances, radically reduces the quantum of inventiveness required for a patent. The old synergy doctrine effectively required an element of new knowledge or know-how by asking for an unexpected result or a result that was greater than the sum of the parts.

In the USA the CAFC has introduced similar restrictions on combining pieces of existing knowledge in relation to the obviousness test. If the connection between the two documents is not available in written form, US patent examiners may not combine this knowledge.

\section{Patent policy and statute law}

Except for some theoretical work and various econometric pieces using available patent data as rather poor proxies for underlying variables, economists in general have paid scant attention to the patent system. An exception was the series of studies undertaken as input to the 1984 IPAC report on the patent system. Billed as an economic evaluation of the patent system, the sole economist on the Committee issued a dissenting report (IPAC 1984: 79-80). Nonetheless the economic input was valuable, including a survey of engineers which clearly demonstrated that industrial researchers do not use patent documentation as a source of information on new technology.

IPAC's recommendations to improve the height of the inventive step focused on allowable existing knowledge. They did not challenge the limitation of the novelty test to a single document, and they actively recommended against allowing combining knowledge from different sources for the inventiveness test. Their recommendations on allowable documents for common general knowledge were not accepted. They were subsequently adopted following the Ergas review (IPCRC 2000). From April 2002 the inventiveness test allowed common general knowledge plus

\footnotetext{
${ }^{36}$ Patent Examiner's Manual, 2.5.3.3.
} 
any published documents as long as it was the PSA who determined the relevance of those documents. In general, however, the Ergas review assumed that the patent system had a genuine inventive step.

In its 2009 review of patentability standards, IP Australia raised the problems created by the Emperor Sports decision, that existing knowledge was frequently deemed inadmissible in judging inventiveness in low technology fields. This problem has been partially addressed in the Patents Amendment Act 2012, and now any knowledge can be used in the inventiveness test provided the PSA would have combined it. It remains to be seen how the courts will interpret this new proviso.

IP Australia also raised the problem of the very low standard for the inventiveness test - that if an inventor would have been led directly as a matter of course and with a high probability of success to a particular outcome then that outcome is not inventive. But in the end they were not prepared to tackle this issue, so the quantum of inventiveness required for a patent in Australia remains a scintilla. ${ }^{37}$ As noted above, at least one judge in the UK has remarked on the very low inventiveness standard used in Australia.

Doctrines emerging from disputes between private parties currently impact substantially on public patent law. Several cases limit what existing knowledge can be used in determining the base against which novelty or inventiveness is assessed. These currently include:

- $\quad$ Limiting novelty assessments to a single document (England 1880, re-emphasised in 1929, 1952 and 1956; simply imported into Australia)

- $\quad$ Narrowly defining the relevant field of technology (Australia, 2001 (Welcome case); also aspects of the 2007 High Court Lockwood case)

Other doctrines set rules for a very low standard for determining inventiveness:

- Requiring only a scintilla of inventiveness (origin English; exact case unclear; citations tend to be Samuel Parkes \& Co. Ltd. v. Cocker Bros. Ltd. (1929) 46 RPC 241, and earlier);

- Setting the standard as being led directly as a matter of course and in clear expectation of success (Australia, 2002 (Hässle case))

- $\quad$ Requiring that combinations of known elements be deemed inventive unless written down or only one such combination probable

(Australia, 1980 (3M case))

These doctrines combine to ensure that a very low inventiveness standard for patents in Australia.

The recent Cutler review of the National Innovation System has recommended that:

"Patent law should be reviewed to ensure that the inventive steps required to qualify for patents are considerable ... so as to minimise litigation and maximise the scope for subsequent innovators."

(Cutler et al. 2008): 86

The minimal change to the inventive step test in the Patents Amendment Act 2012 pays only the merely lip service to this recommendation.

Given that the very low inventiveness standard introduced by case law is so clearly at odds with the economic objectives of the patent system, why has it not been reformed? The Patents Act 1952 created the protected profession of Patent Attorney, a profession similar to the now defunct profession of tariff consultant. This well-paid and numerous ${ }^{38}$ profession is represented on IP

\footnotetext{
${ }^{37}$ Instead they said they would reinforce standards in the Patent Examiner's Manual. Just how better examination will overcome poor case law doctrine is unclear, as it is case law which sets the standards.

${ }^{38}$ The number of registered Patent Attorneys in Australia has grown from around 75 in 1991-95 to over 250 in 2006-10. This $233 \%$ growth in a period of 15 years far outperforms the growth in business expenditure in $R \& D$ during the same period. Data are from the discussion paper on a proposed Trans-Tasman Patent
} 
Australia's advisory committee - unlike the Australian Consumer Association - and Patent Attorneys have also often served on review committees. Academics also serve on such committees and it is a moot point, given that their student numbers depend at least in part on the size and growth rate of the Patent Attorney profession, just how dispassionate their approach to patent law balance is. The absence of economists from discussions on patent policy is almost total. As noted above there was one economist who served on the IPAC review of the patent system - a review that was billed as an economic review. The other members of the review committee were beneficiaries of the patent system. That economist, Professor Don Lamberton, issued a dissent to the committee report, saying, inter alia:

"This Report does not live up to its claim to have adopted an economic perspective and to have applied economic criteria. ... It is constrained by ... special pleading by those directly involved ..."

(IPAC, 1984: 79-80)

Few economists take a serious interest in the patent system, and the current fashion of econometric analysis means that the work that is done makes little sense. When granted patents range from the trivial to the substantial, analysis of patent volume data is next to meaningless, and analysis of patent application data even less so. Likewise proxies such as citations have never been demonstrated to measure the underlying variables (e.g. patent quality) they are supposed to measure. There has been no Productivity Commission inquiry into the patent system.Lawyers retain a virtual monopoly on policy advice on this major area of innovation policy.

Clearly if the Australian patent system is to have any chance of enhancing national economic wellbeing the approach to assessing whether a patent monopoly is merited needs substantial rethinking. Federal Court judges rarely seem to consider the full wording of S.6 of the Statute of Monopolies - despite this being the key definition of a patentable invention in the Patent Act - and if they do they are criticised by their colleagues. As it is the provisos in S.6 that contain the key concepts of benefit to the nation this is unfortunate. Perhaps it is time to seriously consider writing the objectives of patent policy into the Patent Act.

It is clearly time to review the whole construct of the PSA and to abandon the tests of novelty and inventiveness, or at least re-shape these in terms of the critical underlying variable of delivering new knowledge or know-how. A direct and objective test of new knowledge and know-how unmediated by uninventive men - would do much to raise the standard of inventiveness required for grant of an Australian patent. As such it would eliminate many underserved ('bad') patents, while still providing monopolies for genuine improvements and new artefacts and processes.

It would be helpful if economists and students of innovation entered the research arena, and insisted, as a minimum, that the National Innovation Survey contained substantial questions on how innovative firms use patents and how they are affected by the patents held by others. Further it would be timely for the government to implement the 1984 IPAC recommendation that when firms renew their patents they should provide information they use these monopolies. It seems irresponsible to hand out so many thousands of monopolies yet fail to collect any information on their use.

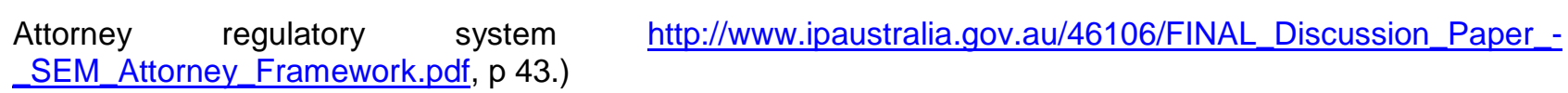




\section{References}

ACIP. 2008. Patentable Subject Matter: Issues Paper

Bagley, M. 2001. "Internet Business Model Patents: Obvious by Analogy." Michigan Telecommunications Technology Law Review, 7: 253-288.

Bochnovic, J. 1982. The Inventive Step: its Evolution in Canada, the United Kingdom and the United States. Munich: Max Planck Institute.

Brennan, D.J. and A.F. Christie. 1997. "Patent Claims for Analogous Use and the Threshold Requirement of Inventiveness." Federal Law Review 25(2): 237-262.

Cohen, J.E. and M.A. Lemley. 2001. "Patent Scope and Innovation in the Software Industry." California Law Review 89(1): 1-57.

Curtis, L.J. and R.T.G. Lahey. 1954. "Subject-Matter for Letters Patent." ANZAAS General Meeting.

Cutler, T. et al. 2008. venturousaustralia - building strength in innovation: Report on the Review of the National Innovation System, Canberra: Department of Innovation, Industry, etc.

FTC. 2003. "To Promote Innovation: The Proper Balance of Competition and Patent Law and Policy." Washington, D.C.

Gans, J.S., P.L. Williams, and D. Briggs. 2004. "Intellectual Property Rights: A Grant of Monopoly or an Aid to Competition?" Australian Economic Review 37(4): 436-445.

IP Australia. 2009a. "Getting the Balance Right: Toward a Stronger and More Efficient IP Rights System."

—. 2009b. "Toward a Stronger and More Efficient IP Rights System: Proposed Reforms."

IPAC. 1984. Patents, Innovation and Competition in Australia, Canberra: AGPS.

IPCRC. 2000. "Review of Intellectual Property Legislation Under the Competition Principles Agreement: Final Report."

Jensen, P.H. and E.M. Webster. 2004. "Achieving the Optimal Power of Patent Rights." Australian Economic Review 37(4): 419-426.

Lawson, C. 2008. "Quantum of Obviousness in Australian Patent Laws." Australian Intellectual Property Journal 19: 43-65.

Thambisetty, S. 2008. "Increasing Returns in the Patent System: Sources and Consequences." ECPR 2008 Workshop 14, The Politics of Intellectual Property, Rennes, 11-16 April.

Tyacke, N.and T. Webb. 2007. "Business Method Patents in Australia and the US: the Difficulties Continue." Australian Intellectual Property Law Bulletin 19(8): 117-122.

van Caenegem, W. 2007. Intellectual Property Law and Innovation. Cambridge: CUP.

Walterscheid, E.C. 1995a. "The Early Evolution of the United States Patent Law: Antecedents (Part 1)" Journal of the Patent and Trademark Office Society (JPTPS), 76(9):697-715.

-. 1995b. "The Early Evolution of the United States Patent Law: Antecedents (Part 2)" JPTPS 76(11): 849880.

Warshofsky, F. 1994. The Patent Wars: The Battle to Own the World's Technology. New York: John Wiley. Wilmot, H.R. 1954. "Some Aspects of the Australian Patent System." ANZAAS General Meeting. 


\section{Appendix 1. Australian Patents Act 1990, Section 7.}

\section{Novelty and inventive step}

\section{Novelty}

(1) For the purposes of this Act, an invention is to be taken to be novel when compared with the prior art base unless it is not novel in the light of any one of the following kinds of information, each of which must be considered separately:

(a) prior art information (other than that mentioned in paragraph (c)) made publicly available in a single document or through doing a single act;

(b) prior art information (other than that mentioned in paragraph (c)) made publicly available in 2 or more related documents, or through doing 2 or more related acts, if the relationship between the documents or acts is such that a person skilled in the relevant art would treat them as a single source of that information;

(c) prior art information contained in a single specification of the kind mentioned in subparagraph (b)(ii) of the definition of prior art base in Schedule 1.

\section{Inventive step}

(2) For the purposes of this Act, an invention is to be taken to involve an inventive step when compared with the prior art base unless the invention would have been obvious to a person skilled in the relevant art in the light of the common general knowledge as it existed in the patent area before the priority date of the relevant claim, whether that knowledge is considered separately or together with the information mentioned in subsection (3).

(3) The information for the purposes of subsection (2) is:

(a) any single piece of prior art information; or

(b) a combination of any 2 or more pieces of prior art information;

being information that the skilled person mentioned in subsection (2) could, before the priority date of the relevant claim, be reasonably expected to have ascertained, understood, regarded as relevant and, in the case of information mentioned in paragraph (b), combined as mentioned in that paragraph.

[Notes: (1) For the meaning of document see section 2B of the Acts Interpretation Act 1901.

(2) See also the definitions of prior art base and prior art information in Schedule 1: see also paragraph 18(1)(b) and subsection 98(1).]

Source: http://www.austlii.edu.au/au/legis/cth/consol act/pa1990109/s7.html 


\section{Appendix 2. Advertisement for ACIP members}

Qualifications are stated in paragraph 3 and emphasise being a beneficiary of IP systems.

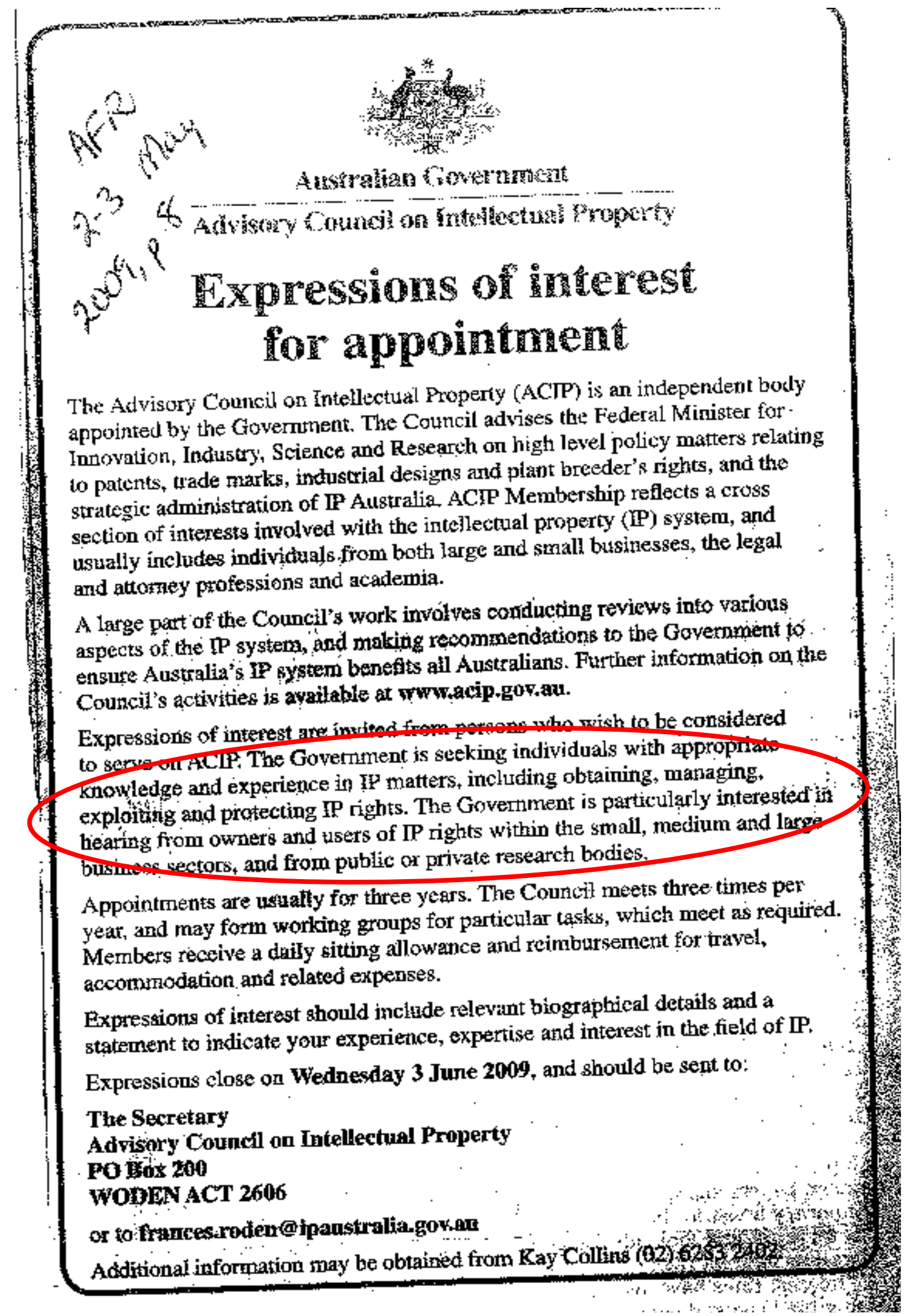

Source: Australian Financial Review, 2-3 May 2009: 8 